\title{
In vivo optogenetics reveals homeostatic control of cochlear sensitivity by supporting cells
}

\section{Victoria Lukashkina}

University of Brighton

Snezana Levic

University of Brighton

Patricio Simões

University of Brighton

Zhenhang Xu

Creighton University School of Medicine

Joseph DiGuiseppi

Creighton University School of Medicine

Jian Zuo

Creighton University

Andrei Lukashkin

University of Brighton https://orcid.org/0000-0003-4577-8716

lan Russell ( $\square$ I.Russell@brighton.ac.uk)

University of Brighton https://orcid.org/0000-0002-4915-2772

\section{Article}

Keywords: In vivo, optogenetics, homeostatic control, cochlear sensitivity, supporting cells

Posted Date: October 20th, 2020

DOI: https://doi.org/10.21203/rs.3.rs-92461/v1

License: (c) (1) This work is licensed under a Creative Commons Attribution 4.0 International License.

Read Full License 
1 In vivo optogenetics reveals homeostatic control of cochlear sensitivity by

2 supporting cells

3
Authors: Victoria A. Lukashkina ${ }^{1}$, Snezana Levic ${ }^{1,3}$, Patricio Simões ${ }^{1 \dagger}$, Zhenhang $\mathrm{Xu}^{2}$, Joseph A. DiGuiseppi ${ }^{2}$, Jian Zuo $^{2 *}$, Andrei N. Lukashin ${ }^{1^{*}}$, Ian J. Russell ${ }^{1^{*}}$

\section{Affiliations:}

${ }^{1}$ Sensory Neuroscience Research Group, School of Pharmacy and Biomolecular Sciences, University of Brighton, Huxley Building, Brighton, BN2 4GJ, UK

${ }^{2}$ Department of Biomedical Sciences, Creighton University School of Medicine, 2500 California Plaza, Omaha, NE 68178, USA

${ }^{3}$ Brighton and Sussex Medical School, University of Sussex, Brighton BN1 9PX, UK. ${ }^{\dagger}$ Current address: Sussex Neuroscience, School of Life Sciences, University of Sussex, Brighton BN1 9QG, UK

*Correspondence to: A.Lukashkin@brighton.ac.uk, I.Russell@brighton.ac.uk, JianZuo@creighton.edu

\section{ABSTRACT:}

We used optogenetics to investigate the control of auditory sensitivity by cochlear supporting cells that scaffold outer hair cells, which transduce and amplify cochlear responses to sound. In vivo and in vitro measurements of sound-induced cochlear mechanical and electrical responses were made from mice that conditionally expressed nonselective cationic channelrhodopsins in Deiters' and outer pillar supporting cells in the organ of Corti. We demonstrated that cochlear light-stimulation and subsequent activation of channelrhodopsins depolarized the supporting cells, changed their extracellular electrical environment, and sensitized insensitive and desensitized sensitive cochlear responses to sound. We concluded that outer hair cells, Deiters' cells and outer pillar cells interact through feedback which regulates their immediate ionic and electrical environment and controls energy flow in the mammalian cochlea to optimize its performance over its entire dynamic range. Activation of the supporting cell channelrhodopsins shunts this feedback system and restores cochlear sensitivity to a set level. 


\section{INTRODUCTION}

A striking feature of the mammalian sensory auditory epithelium, the organ of Corti (OC) of the cochlea, is the cellular architecture and arrangement of the so-called supporting cells that provide a structural scaffold for the sensory hair cells ${ }^{1}$. However, to date there have been no direct in vivo evidence to show how supporting cells interact with hair cells to provide the cochlea's sensitive, sharply tuned, responses to sound stimulation. The OC (Fig. 1a) is attached to the extracellular matrix of the basilar membrane (BM), which spirals in graded stiffness and frequency selectivity from the low-frequency apex to the high-frequency base of the coiled cochlea, thereby spatially separating individual frequency components of complex sounds into different locations on the BM according to the so-called characteristic frequency (CF) of their location ${ }^{2}$. Of the two types of sensory cells located in the OC, the electromotile outer hair cells (OHCs) ${ }^{3-5}$ sense sound evoked BM vibrations through displacements of the hair bundles, which alter the gating probability of mechanoelectrical transduction (MET) channels located near the tips of the stereocilia that comprise the hair bundles ${ }^{6}$. Flow of predominantly $\mathrm{K}^{+}$current through the MET conductance, which is modulated during BM sound-induced vibration ${ }^{6}$, is driven by the batteries of the endocochlear potential (EP) and OHC resting potential in series ${ }^{7}$. The $\mathrm{OHC}$ MET currents generate receptor potentials that produce transmembrane voltage differences which control ultrafast $\mathrm{OHC}$ electromotility that power-amplifies and sharpens cochlear mechanical responses locally to frequencies close to the $\mathrm{CF}^{2,8}$. OHC electromotility, and resultant cochlear amplification, is mediated by a protein prestin, which is abundantly present in the $\mathrm{OHC}$ lateral membrane and changes its conformation in response to $\mathrm{OHC}$ transmembrane voltage changes ${ }^{8}$. The OHCs operate within a structural scaffold of supporting cells, the outer pillar cells (OPCs) and Deiters' cells (DCs), which encompass fluid-filled spaces of Nuel (SN) that envelope the lateral 
membranes of the OHCs (Fig. 1a). The supporting cells, especially the DCs, are crucially located to play instrumental roles in the passive and active transmission of forces from $\mathrm{OHCs}$ to the structures of the cochlear partition and to control $\mathrm{OHC}$ axial loading ${ }^{9,10}$. The apical poles of the motile DCs ${ }^{11,12}$, which also contribute to the OC electrical conductance ${ }^{13,14}$, support the OHCs and transmit their forces to the cochlear partition. The long, stiff, phalangeal processes of the DCs mechanically link the basal and apical poles of the OHCs, forming a perfect feedback system for controlling the mechanoelectrical energy flow within the OC and hence cochlear sensitivity $\left({ }^{15,16}\right.$, Fig. 1a). Thus, OHCs are enclosed in a potential control system that could regulate their sensitivity through changes to their mechanical, electrical, and ionic environment.

To test this hypothesis in vivo, we have exploited optogenetics and used mice with conditional expression of COP-tdTomato channelrodopsin (COP) specifically in the DCs and OPCs (Supplemental Methods and Fig. 1b-g). This approach provided the opportunity to examine the involvement of DCs and OPCs in controlling the sensitivity of the cochlea and revealed a novel homeostatic system of cochlear sensitivity regulation.

\section{RESULTS}

\section{Specific inducible expression of COP in cochlear supporting cells}

To induce COP expression specifically in mature DCs and PCs in the organ of Corti of the cochlea, we used a previously characterized Fgfr $3-\mathrm{iCreER}^{\mathrm{T} 2}$ mouse line that displays $\sim 100 \%$ inducible Cre activity in cochlear DCs and PCs when tamoxifen was injected at juvenile and adult ages ${ }^{17,18}$. When induced at postnatal days 12 and 13 (P12/13) or P21, Fgfr3iCreERT2+; COP-tdTomato+ experimental mice showed robust expression of COPtdTomato fusion protein specifically in both DCs and PCs within the organ of Corti at P28, whereas no COP-tdTomato was detected in DCs/PCs in Fgfr3-iCreERT2-; COP-tdTomato+ 
control mice at P28 (Fig. 1b-g; see Methods). No expression of COP-tdTomato fusion protein was detected in stria vascularis or any other cochlear structures of Fgfr3-iCreERT2+; COPtdTomato + experimental mice when induced at P12/13 and analyzed at P21/22. These results on COP specific expression in DCs and PCs in the cochlea are consistent with previous studies ${ }^{17-19}$.

a

Reticular lamina (RL) Outer pillar cell (OPC) Spaces of Nuel (SN) Basilar membrane (BM)

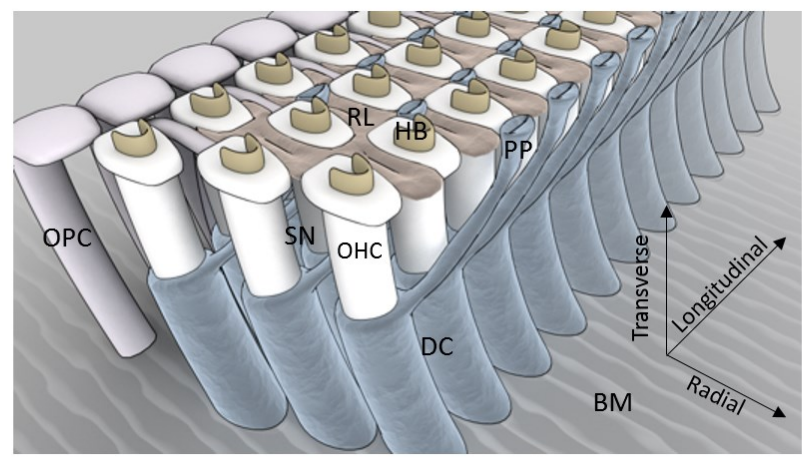

Hair bundle (HB) Outer hair cell (OHC) Phalangeal process (PP) Deiters' cell (DC)
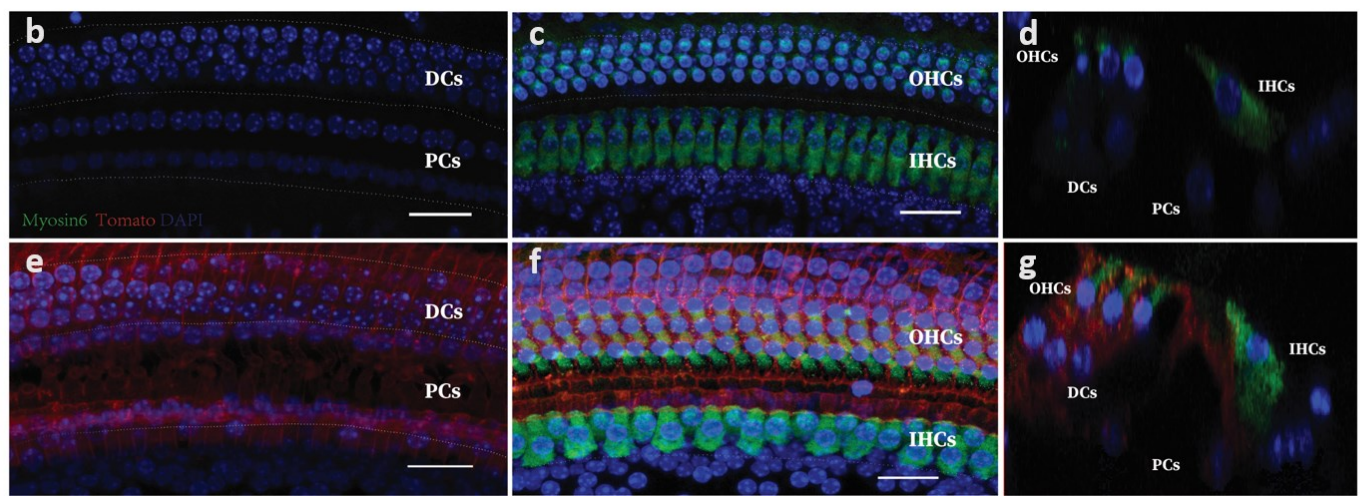

Figure 1. Schematic of the organ of Corti and expression of COP-tdTomato ChR in its supporting cells. (a) Schematic of the radially distal region of the organ of Corti. (b-g) ChR expression in the DCs and inner and outer pillar cells (PCs). Fgfr3-iCreER ${ }^{\mathrm{T} 2}$; COP-tdTomato mice were induced with tamoxifen (TMX) at P12/13 and analyzed at postnatal-day 28. (b-d) Fgfr3-iCreER ${ }^{\mathrm{T} 2-}$; COP-tdTomato ${ }^{+}$control mice. (e-g) Fgfr3-iCreER ${ }^{\mathrm{T} 2+}$; COPtdTomato $^{+}$experimental mice. (b,c,e,f) wholemount cochlear basal turns. (b,e) supporting cell layers. (c,f) projections of supporting cell and hair cell layers. $(\mathbf{d}, \mathbf{g})$ optical cross-sections in $(\mathbf{b}, \mathbf{c})$ and $(\mathbf{e}, \mathbf{f})$ respectively. IHCs: inner hair cells. Green: Myo6; blue: DAPI; red: autofluorescence of tdTomato. Scale bar = 20um.

\section{Cochlear illumination depolarizes COP mouse DC membrane potentials and reduces}

\section{the endocochlear potential.}


97 COP is a light-sensitive cation selective channel ${ }^{20,21}$. When activated by light, COPexpressing DCs are depolarized (Fig. 2a,b) with increased conductance (Fig. 2c), which was not observed in wild-type littermates in whole cell patch recordings from ex vivo flatmounted preparations of the OC. Depolarization, similar in magnitude to that recorded from ex vivo COP expressing DCs, was recorded from presumed COP-expressing DCs (resting potentials; $-108.5 \pm 8.7 \mathrm{mV}, \mathrm{n}=25 \mathrm{DCs}$ in 14 cochleae) when activated by illumination of the BM and recorded with an intracellular micropipette in vivo (Fig. 2d,f). When advanced (see Supplemental Methods) through the DCs, the micropipette encountered the positive $(+114.3 \pm 3.7 \mathrm{mV}, \mathrm{n}=11$ mice) endocochlear potential (EP) of the scala media (Fig. 2e), one of the batteries in series that drives receptor current through the gated OHC MET conductance. At BM illumination onset, the EP was reduced by $\sim 1 \mathrm{mV}$, which lasted without decline for $1-3 \mathrm{~s}$ followed by a steady decline in EP throughout the duration of the illumination, falling by $23 \mathrm{mV} \pm 4 \mathrm{mV}$ in $40 \mathrm{~s}, \mathrm{n}=6$. EP fully recovered to pre-illumination levels when measured 3 to 5 minutes after BM illumination. Light-activated changes in EP described above were not encountered in littermates that did not express COP in the DCs and OPCs (Fig. 2e, WT trace). Altogether, these findings indicate that the DCs and OPCs are essential components of the cochlear electrical network ${ }^{13,14}$ and their potential and conductance changes can control the EP. 


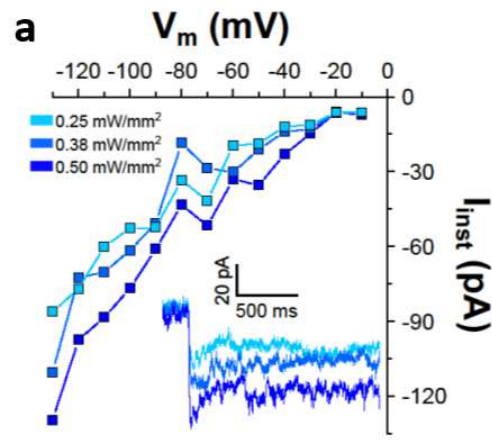

b

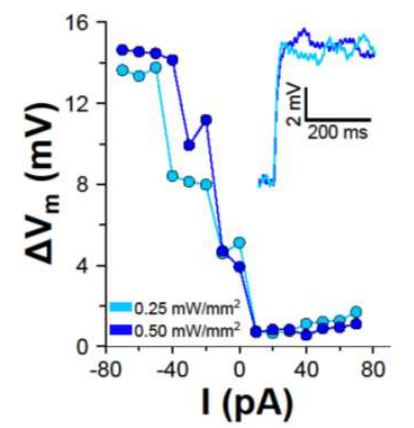

c

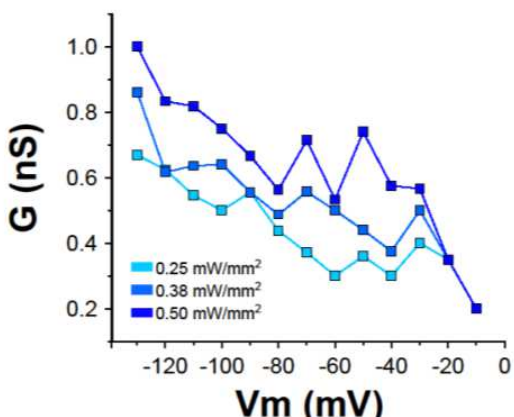

d

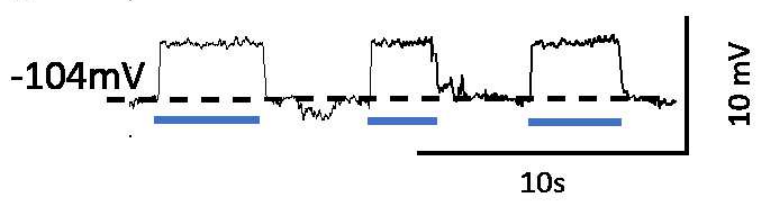

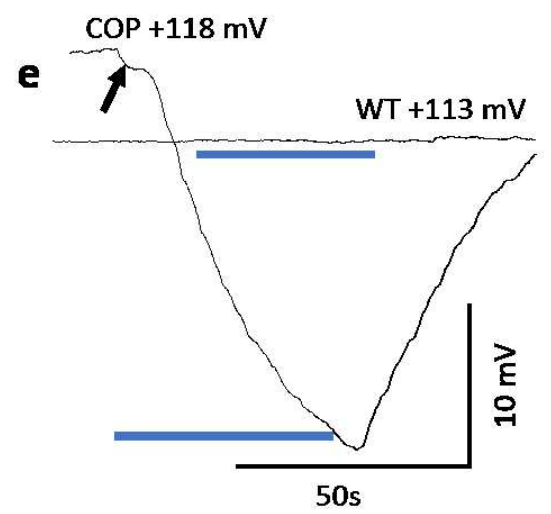

Figure 2. Cochlear illumination depolarizes COP mouse DC membrane potentials and reduces the endocochlear potential. (a) Ex vivo whole-cell patch recordings of current-voltage (I-V) plot: peak current amplitudes of a DC elicited in response to laser illumination at different power densities, as functions of membrane potential. Inset: Inward current traces at different laser power densities (-90 $\mathrm{mV}$ holding potential). (b) Ex vivo light-induced potential-current $(\Delta \mathrm{V}-\mathrm{I})$ relationship of a DC: membrane potential changes $(\Delta \mathrm{V})$ during laser illumination as functions of injected currents. Light-induced depolarizations were elicited during negative current injection. Inset: whole-cell current-clamp recording (resting membrane potential $=-50 \mathrm{mV}$ ) of light elicited depolarization with different laser power densities. (c) Conductance $\mathrm{G}(\mathrm{nS})$ as a function of membrane potential $\mathrm{V}(\mathrm{mV})$ at 3 different laser power densities using data in (a) at $-130 \mathrm{mV}$ holding potential. Increasing laser power increased the DC membrane conductance ( $0.67,0.86$ and $1 \mathrm{nS}$ respectively). (d) In vivo intracellular recordings from presumed DCs showing membrane depolarizations $(4.2 \pm 0.3 \mathrm{mV}, \mathrm{n}=8$ cochleae) to successive periods of BM laser illumination. (e) EP recorded from scala media during BM laser illumination. COP trace arrow: onset step. WT littermate: nonresponsive to laser illumination. Blue bars in $\mathbf{d}$ and e: periods of $100 \mu \mathrm{m}$ diameter, 0.25 $\mathrm{mWmm}^{-2}, 470 \mathrm{~nm}$ laser illumination. 

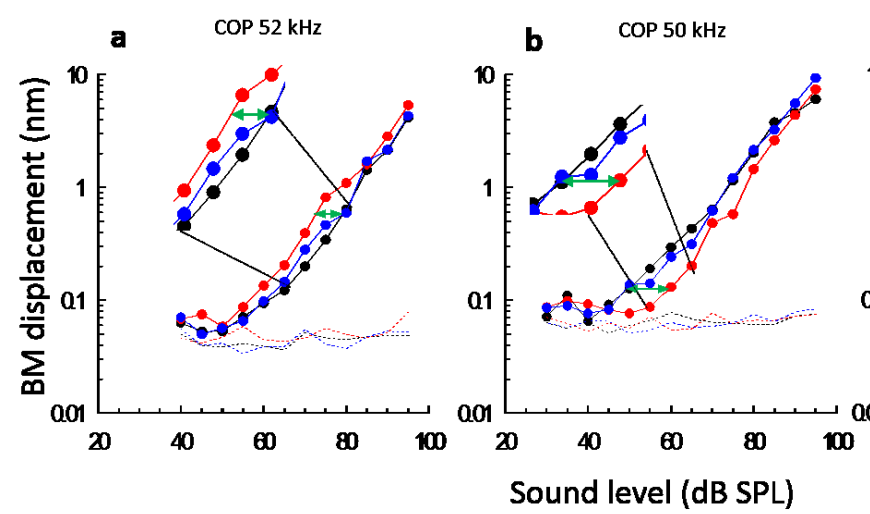
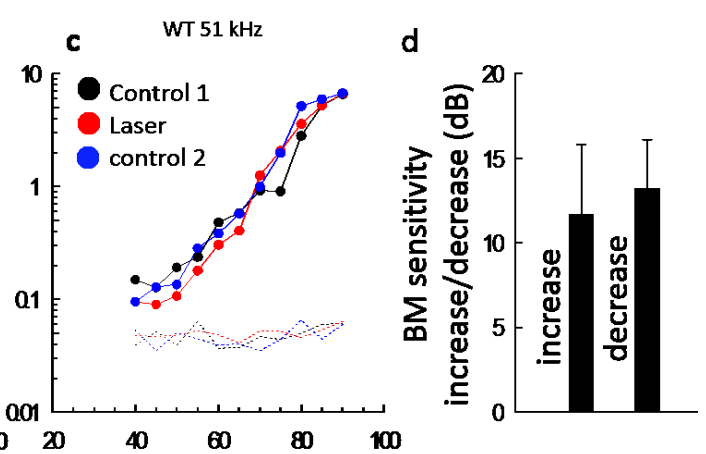

Figure 3. BM Laser illumination alters the sensitivity of cochlear mechanical responses of COP mice over their entire dynamic range. (a-c) BM displacement as functions of SPL from two COP (a,b) and one WT (c) mice at the $\mathrm{CF}$ tone frequencies indicated. Measurements were, made before (black, control 1), during (red, laser), and following (blue, control 2) BM laser illumination (see c). Dotted lines: measurement noise floors Green arrows (a,b): maximum sensitivity change (expanded views: insets). d. Mean \pm S.D of maximum increases in sensitivity $(11.7 \pm 4.1 \mathrm{~dB}, \mathrm{n}=7$ cochleae $)$ and decreases $(13.2 \pm 2.9 \mathrm{~dB}, \mathrm{n}=9)$ of BM displacement (green arrows a,b) during BM laser illumination in COP mice. There was no visible increase or decrease of BM sensitivity in WT littermates ( $-1.3 \pm 2.2 \mathrm{~dB}, \mathrm{n}=6$ cochleae $)$. Laser illumination: $100 \mathrm{~mm}$ beam diameter, wavelength: $473 \mathrm{~nm}$, power density $=0.25 \mathrm{mWmm}^{-2}$ apart from $\mathrm{C}=0.75 \mathrm{mWmm}^{-2}$. All measurements from different cochleae, uncompensated for middle-ear and electrode characteristics.

To examine how light-activated COP-expressing supporting cells influence cochlear mechanical sensitivity, we measured the dependence of BM displacement on sound pressure level (SPL). Cochlear mechanical responses to CF and near CF tones are sensitive and increase compressively with moderate to high SPL, indicating cochlear amplification ${ }^{2}$. We measured $\mathrm{BM}$ displacement level functions in response to $\mathrm{CF}$ and near $\mathrm{CF}$ tones from $\mathrm{COP}$ mice (Fig. 3, a.b) and control littermates (WT, Fig. 3c) to discover if illumination of the BM measurement site with a laser beam through the closed $\mathrm{RW}$, in the $50 \mathrm{kHz}-60 \mathrm{kHz}$, basal region of the cochlea influenced BM level functions and hence cochlear sensitivity. BM laser 
illumination in COP (Fig. 3a,b,d), but not WT littermates (Fig. 3c), caused reversible increases or reversible decreases in cochlear BM sensitivity throughout its dynamic range to tones at the $\mathrm{CF}$ of the recording site. The sensitivity changes occurred during BM illumination and returned to control levels within $35-70$ s after illumination. BM laser illumination of six WT littermates caused no measurable magnitude changes in BM level functions (Fig. 3c).

Light-activation of COP-expressing supporting cells changes extracellular OHC toneevoked electrical responses.

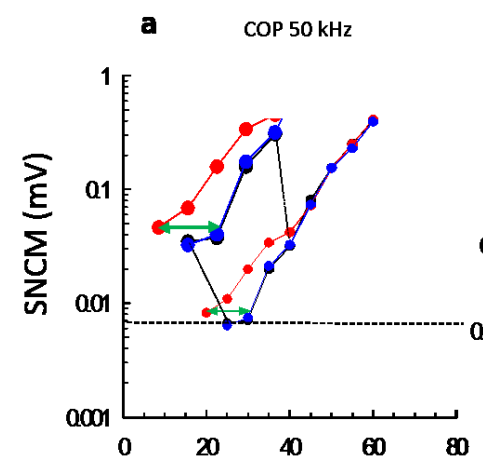

Figure 4. BM Laser illumination alters the sensitivity of cochlear electrical responses that are subject to cochlear amplification in COP mice. (a-b) Organ of Corti cochlear microphonic potential recorded from the SN (SNCM); magnitude as functions of SPL for sound stimulation at the CF frequencies indicated.

Measurements made before (black), during (red), and following (blue) BM laser illumination (see 3c). Dotted lines: mean measurement noise floors. Green arrows: maximum sensitivity change (expanded views: insets). d. Mean \pm S.D of maximum increases in sensitivity $(12.4 \pm 3.2 \mathrm{~dB}, \mathrm{n}=8$ cochleae $)$ and decreases $(14.1 \pm 3.3 \mathrm{~dB}, \mathrm{n}$ $=7$ ) of SNCM (green arrows a,b) during BM laser illumination in COP mice. There was no visible increase or decrease of BM sensitivity in WT littermates $(0.7 \pm 1.8 \mathrm{~dB}, \mathrm{n}=5$ cochleae $)$. Laser illumination; $100 \mathrm{~mm}$ beam diameter, wavelength: $473 \mathrm{~nm}, \mathbf{a , b}$; power density $=0.25 \mathrm{mWmm}^{-2}, \mathrm{C} ;=0.75 \mathrm{mWmm}^{-2}$. All measurements from different cochleae, uncompensated for middle-ear and electrode characteristics. 
We measured the magnitude and phase of extracellular voltage responses or microphonic potential recorded from the spaces of Nuel (SNCM) of the OC of COP and WT mice as a function of SPL (level functions) in response to CF and near CF tones, with and without BM illumination in the $50 \mathrm{kHz}-60 \mathrm{kHz}$ region of the cochlea. Tone-evoked voltage responses recorded in the $\mathrm{OC}$ vary considerably with the location of the recording site ${ }^{22}$. We found the largest to be from the SN immediately adjacent to the OHCs and DCs. The SNCM is the voltage produced across the resistive network of the $\mathrm{SN}^{23}$ by the flow of the MET current, dominated by $\mathrm{K}+$ which flows outwards, down its electrochemical gradient, across the basolateral membranes of the OHCs, where it accumulates in the fluid spaces of the $\mathrm{OC}^{22}$. Excess $\mathrm{K}+$ is "siphoned" by electro-neutral $\mathrm{K} / \mathrm{Cl}$ co-transporters in the adjacent $\mathrm{DCs}{ }^{24,25}$ and cleared from the DC cytoplasm via an intercellular gap junctional pathway ${ }^{26}$, thereby preventing prolonged depolarization of the $\mathrm{OHC}$ membrane potential. At low-levels $(0-40$ dB SPL), SNCM is dominated by the amplified responses of OHCs to tones centered on the cochlear frequency place of the measurement location. With increasing level above $\sim 40 \mathrm{~dB}$ SPL, OHCs from adjacent frequency regions contribute to the SNCM due to spread of excitation ${ }^{27}$. In 9 sensitive mice (CF thresholds $16.5 \pm 3.2 \mathrm{~dB}$ SPL), light-activation of DCs and OPCs either increases and/or decreases (Fig. 4a,b,d) the sensitivity of SNCM responses to $\mathrm{CF}$ and near $\mathrm{CF}$ tones for stimulus levels within $\sim 30 \mathrm{~dB}$ SPL of threshold. Light activation of DCs and OPCs had little influence on SNCM responses for levels above this. Soundevoked electrical responses recorded in the SN of five WT littermates to CF tones remained unchanged by BM laser illumination, even when the laser power greatly exceeded the threshold for COP-activation (Fig. 4c). Light-activation of COP-expressing DCs and OPCs can, therefore, increase or decrease the mechanical responses of the $\mathrm{BM}$ to $\mathrm{CF}$ tones throughout its dynamic range, but only influences $\mathrm{OHC}$ tone-evoked electrical responses to levels that are subject to cochlear amplification $(<50 \mathrm{~dB}$ SPL $)$. 
Light-activation of COP-expressing supporting cells accelerates sensory recovery of temporarily desensitized cochleae.

Brief exposure to loud sounds can temporarily desensitize the cochlea for seconds to minutes

28. Cochlear desensitization of about $15 \mathrm{~dB}$ (green arrows, Fig. 5a, b) occurred when the required 5-minute recovery period between successive level function measurements, which include high-level (80dB SPL) sound exposures, was omitted. Illumination of the BM in COP measurements and cochlear sensitivity returned immediately to control levels.
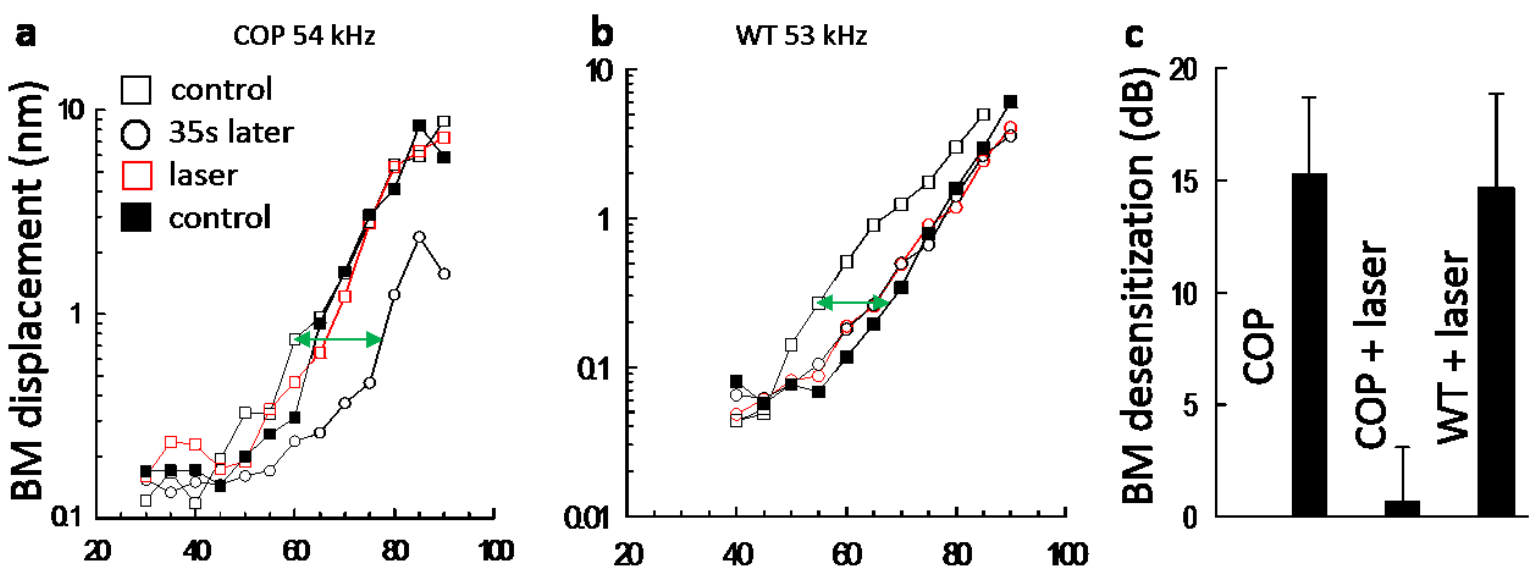

Sound level (dB SPL)

Figure 5. BM Laser illumination of COP mice accelerates recovery of temporarily desensitized cochleae.

a: BM displacement level functions measured in COP mouse in quick succession (35s intervals) after control (open squares), without required 5-minute interval, becomes desensitized (open circles). Sensitivity returns during the level run with BM laser illumination (red squares), measured 35s after the open circle level run. Sensitivity is sustained during control level run (black solid squares), measured 35s after laser run. b. BM displacement level functions measured in WT mouse using the same regime as for the COP mouse in a. Maximum sensitivity change: green arrows (a,b). c. Bar graphs: maximum change in BM displacement sensitivity to CF tone level functions presented successively in $35 \mathrm{~ms}$ intervals in COP mice without BM laser illumination $(15.3 \pm 3.4 \mathrm{~dB}, \mathrm{n}=6$ cochleae $)$ and in $\operatorname{COP}(0.7 \pm 2.4 \mathrm{~dB}, \mathrm{n}=6)$ and WT mice $(14.7 \pm 4.1 \mathrm{~dB}, \mathrm{n}=$ 
216 5) with laser illumination. Laser illumination: $100 \mathrm{~mm}$ beam diameter, wavelength: $473 \mathrm{~nm}$, power density =

$217 \quad 0.25 \mathrm{mWmm}^{-2}$ apart from $\mathbf{c}=0.75 \mathrm{mWmm}^{-2}$. All measurements uncompensated for middle-ear and electrode

218 characteristics.

219 A role for DCs and OPCs in controlling cochlear sensitivity.

220 A role for supporting cells in controlling cochlear sensitivity became apparent in recordings

221 from preparations with fluctuating sensitivity due to preceding high-SPL stimulation. The cochlear sensitivity fluctuated with a period of about 10 minutes and measurements were made at 5-minute intervals that fell in either hyper- or hyposensitivity phases. When these level functions were superimposed, responses measured during BM laser illumination tended to overlie each other regardless of whether BM illumination increased, or decreased the sensitivity of BM displacement and voltage response relative to the control measured just before each period of illumination (Fig. 6a, b). Light-activation of COP-expressing DCs and OPCs reduced the sensitivity of very sensitive BM responses and increased the sensitivity of active homeostatic system that returned cochlear sensitivity to a set level.
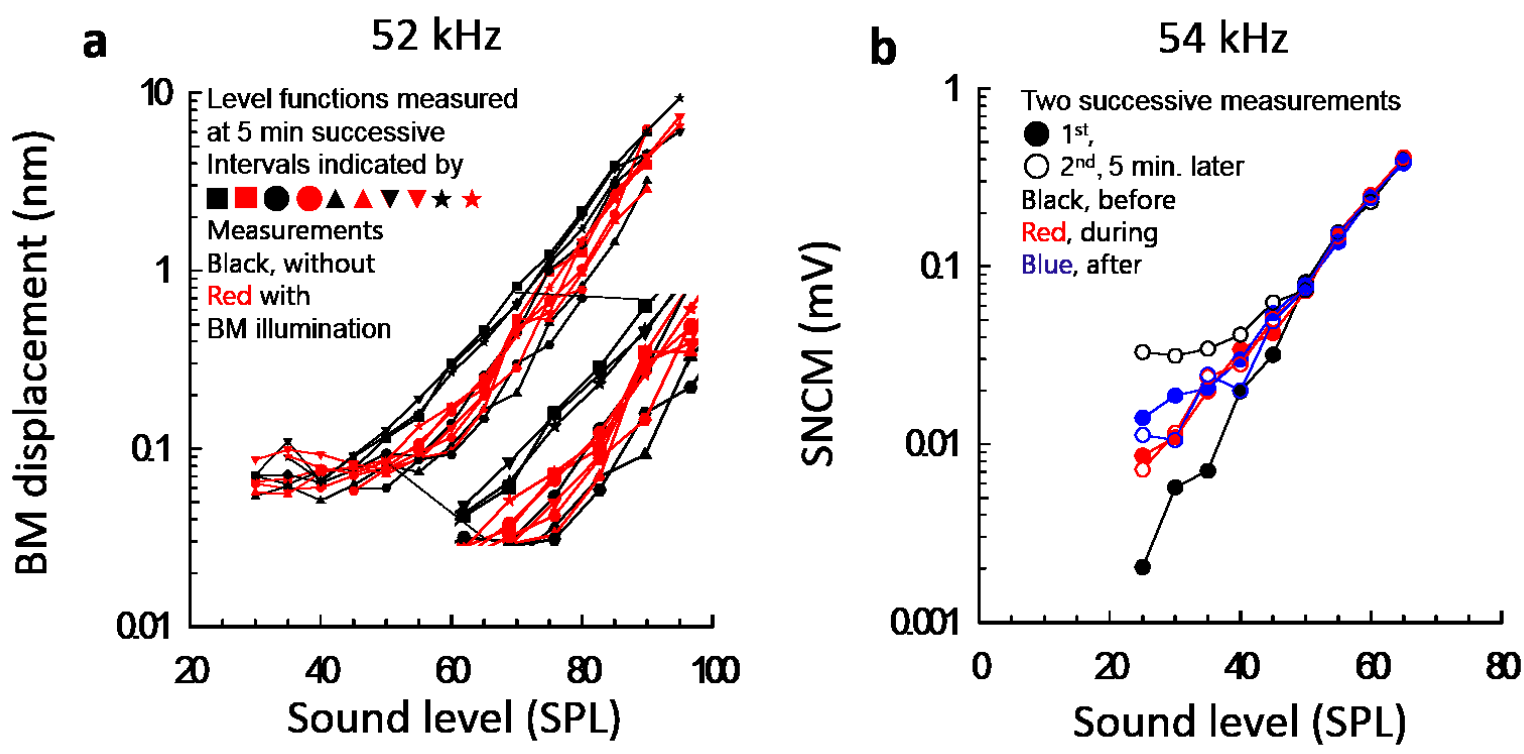
Figure 6. OC supporting cells mediate homeostatic control of mechanical and electrical cochlear sensitivity. (a) BM displacement level functions for CF tones, with expanded view (arrows), showing 10 successive presentations (indicated by different symbols), measured at 5-minute intervals without and with BM laser illumination of a representative cochlea. (b) SNCM level functions for CF tones showing two successive presentations at 5-minute intervals measured during and following BM laser illumination, $473 \mathrm{~nm}, 0.25$ $\mathrm{mWmm} \mathrm{m}^{-2}$

\section{Light-activation of COP-expressing DCs and OPCs changes the polarity of the tonic} component of the SNCM.

During moderate to intense acoustic stimulation, the SNCM recorded in responses to near $\mathrm{CF}$ and $\mathrm{CF}$ tones develops a tonic, time-dependent, positive potential that increases with increasing SPL (Fig. 7a, b). For sound levels greater than about $70 \mathrm{~dB}$ SPL, the tonic component of the OCCM takes the form of a sharp depolarization of a few $\mathrm{mV}$ that declines over 10 s of $\mathrm{ms}$ to zero $\mathrm{mV}$, as has been reported previously ${ }^{22}$. At tone-offset, the $\mathrm{SN}$ becomes negative and recovers to zero over a time periods of $10 \mathrm{~s}$ of

a

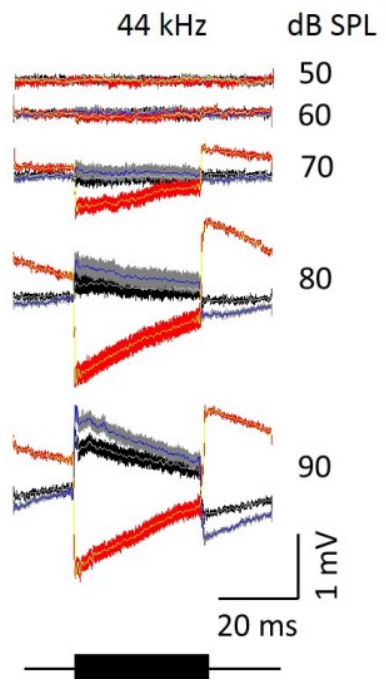

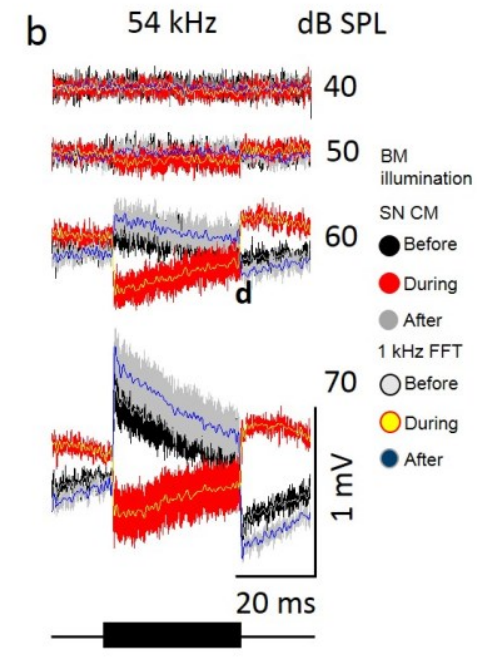

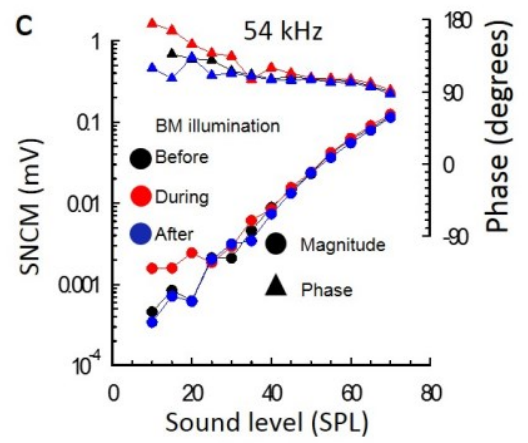

Figure 7. Light excitation of $\mathrm{OC}$ supporting cells changes the polarity of the tonic component of the OCCM in COP mice. (a,b) Voltage responses (average of 20 presentations) to just below CF (44 kHz) and CF $(54 \mathrm{kHz})$ tones recorded from the SN in different cochleae for the SPLs indicated before, during and after BM illumination. Superimposed traces: $1 \mathrm{kHz}$ low-pass FFT filtered responses (tonic component of OCCM). (c) 
SNCM magnitude and phase level functions for data in (b). BM laser illumination: $473 \mathrm{~nm}, 0.25 \mathrm{mWmm}^{-2}$. Bars beneath traces indicate stimulating tone burst.

ms (Figs. 7a, b). These observations have been attributed to the accumulation and clearance of $\mathrm{K}+$ from the $\mathrm{SN}{ }^{22,28}$. BM illumination in COP mice caused the tonic component of the SNCM to be reversed. The tonic component becomes a sharp, time-dependent negative potential that becomes positive at tone offset, returning to zero potential over periods of $10 \mathrm{~s}$ of ms (Figs. 7a, b). Presumably, light-activation of the non-selective cation conductance of COP-expressing DCs and OPCs, their consequent conductance increases and depolarization, changes the properties of the electrical network of the $\mathrm{OC}^{23}$. For levels above about $40 \mathrm{~dB}$ SPL, however, the phase and magnitude of the SNCM remain unchanged (Fig. 7c), an indication that the SNCM tonic potential polarity change does not influence $\mathrm{OHC}$ excitation.

\section{DISCUSSION}

The in vivo measurements reported here support the proposal that OHCs are enveloped by a control system of specialized supporting cells that regulates passive and active mechanical energy flow in the cochlea through sound-induced mechanical and electrochemical changes in the OC. The mechanical and electrical changes we measured from the cochleae of COP mice were initiated when the nonselective cation conductances expressed in DCs and OPCs were gated by laser illumination, as demonstrated in ex vivo and in vivo electrophysiological recording from single DCs (Fig. 2a-d). In this initial investigation, we demonstrated that illumination increased the membrane conductance and depolarized the cells.

The earliest studies, using caged calcium in single cell preparations, revealed that DCs exhibit $\mathrm{Ca}^{2+}$ dependent motility ${ }^{11}$. Depolarization of DCs and OPCs could increase intracellular $\mathrm{Ca}^{2+}$ levels due to influx through the gated COP channels and/or through ATP mediated $\mathrm{Ca}^{2+}$ release from intracellular stores, as had been suggested for fast and slow $\mathrm{Ca}^{2+}-$ 
wave propagation in developing and adult DCs ${ }^{29,30}$. This form of motility may underpin the BM passive motility, which extends over the entire dynamic range of the BM sound-evoked vibrations that we observe in vivo. Depolarization causes mechanical changes in the DCs that include increases in the curvature of the DC phalangeal processes ${ }^{11,12,31}$ and increased turgor pressure ${ }^{31}$. Mechanical changes in DCs cause changes in the turgor pressure of isolated OHCs, which modulates $\mathrm{OHC}$ electromotility and is predicted to modulate cochlear amplification ${ }^{31,32}$, which is what we have observed here. However, perhaps more significant, but yet to be investigated, is that in parallel with changes in OHC electro-mechanical sensitivity ${ }^{31}$, changes to the mechanical properties of the DCs and OPCs alters impedance matching between the OHCs and their supporting cell scaffold ${ }^{33}$. Similar effects in vivo could account for our finding that, while $\mathrm{OHC}$ voltage responses to $\mathrm{CF}$ and near $\mathrm{CF}$ tones are sensitive to COP light activation only over those levels that are susceptible to cochlear amplification, BM displacements are sensitive to light activation over their entire dynamic range and at levels and frequencies that have no observable influence on magnitude and phase of OHC SNCM. These findings appear to indicate that these DC and OPC can induce mechanical changes in the cochlear partition which do not influence OHC MET. However, lack of observable effect of light activation on SNCM at higher stimulus levels may be due to summation and cancelation effects because of spread of the OC electrical potentials with increasing stimulus level (e.g. ${ }^{34}$ ).

We also observed that light activated conductance changes in DCs and OPCs reduced the EP. The initial effect, which was to reduce the EP by about a millivolt, is likely due to light activated gating of the COP channels. The long-term slow effect that commenced 1-3 s after the initial EP reduction reduced the EP by around $20 \mathrm{mV}$. The basis of this long-term reduction requires further investigation but could involve the gap junctions that interconnect supporting cells of the $\mathrm{OC}$, purinergic excitation and $\mathrm{Ca}^{2+}$-signaling ${ }^{35,36}$. Furthermore, a 
$\sim 20 \%$ reduction in EP (Fig. 2e) has little influence on OHC extracellular voltage responses recorded from the $\mathrm{OC}$, as has been reported previously ${ }^{14,37}$.

The mouse cochlea, especially the high frequency region, is susceptible to temporary desensitization, which is also observed in guinea pigs ${ }^{38}$. For this reason, several minutes were left between each level run measurement. If these were missed, the cochlear became desensitized and only returned to full sensitivity after 5 minutes rest. Illumination of the BM in COP, but not wild type mice, restored sensitivity almost immediately. It appears that depolarization of DCs and OPCs accelerates recovery from desensitization.

When exposed to a train of moderately loud tones at a frequency about a half octave below the $\mathrm{CF}$, OHCs slowly become increasingly depolarized over time during the presentation of a train of tones ${ }^{38}$. By contrast, the OC NS becomes sharply depolarized at tone onset, which declines over time and results in hyperpolarization at tone offset and recovers over time as revealed by ${ }^{22}$ and confirmed by SN measurements reported here. The loud tones were suggested to cause cytoplasmic accumulation of $\mathrm{K}^{+}$, which depolarized the OHCs and travelled down its concentration gradient across the $\mathrm{OHC}$ basolateral membranes into the $\mathrm{SN}$ ${ }^{7}$. Following hair cell transduction, the resting perilymphatic $\left[\mathrm{K}^{+}\right]$is raised locally by several $\mathrm{mM}^{22}$, which is syphoned away by electro-neutral $\mathrm{K}^{+} / \mathrm{Cl}^{-}$co-transporters in the adjacent DCs ${ }^{24,25}$, thereby preventing prolonged depolarization of the $\mathrm{OHC}$ membrane potential. This transport mechanism is presumed to be facilitated by a constant clearance of $\mathrm{K}^{+}$from the $\mathrm{DC}$ cytoplasm via an intercellular gap junctional pathway ${ }^{26}$. The different time courses of $\mathrm{K}^{+}$ accumulation and removal in OHCs and the SN might be expected to result in timedependent driving voltages for generating the time-varying amplitudes of the tonic (DC) components of the intracellular OHC receptor potential and extracellular SNCM.

Nevertheless, the kinetics of these processes for high level and/or prolonged acoustic stimulation results in cochlear desensitization because the DCs and OPCs are not able to 
remove $\mathrm{K}^{+}$quickly enough. Light activation of the non-selective cation channels expressed in the DCs and OPCs of COP mice and consequent DC and OPC depolarization overcomes this desensitization, presumably by increasing the ability of DCs and OPCs to buffer and recycle $\mathrm{K}^{+}$at a faster rate. DCs have resting membrane potentials more negative than $-100 \mathrm{mV}$, which is more negative than the expected equilibrium potential of $\mathrm{K}^{+}$in the $\mathrm{SN}$, and the $\mathrm{OHC}$ cytoplasm. When the COP channels are gated, $\mathrm{K}^{+}$would be expected to flow down this steep electrochemical gradient into the DCs and OPCs, which might account for the changed polarity of the tonic component of the SNCM during BM illumination. Regardless of the mechanism, the gating of non-selective cation channels in DCs and OPCs reduces the period of cochlear insensitivity following a loud tone.

Fluctuations in cochlear sensitivity (Fig. 6) provides evidence that OHCs and their closely associated supporting cells interact continuously to make fine adjustments to hearing sensitivity, possibly due to tone induced fluctuations in extracellular $\mathrm{K}^{+22}$. Light activation of nonselective cation channels and the consequent rapid shunting of $\mathrm{K}^{+}$effectively shunts this interaction and the system settles to a quiescent steady state (Fig. 6), presumably by minimizing the $\mathrm{SN} \mathrm{K}^{+}$levels. This finding may provide a basis for why a higher density of cation channels is not normally expressed in DCs and OPCs. When activated in COP mice, their increased conductance effectively short-circuits the mechanism that fine controls cochlear sensitivity. Another reason for the limited $\mathrm{K}^{+}$buffering abilities of supporting cells might originate from apparent lack of selective evolutionary pressure that favors the expression of such a system that ensures rapid recovery from temporary threshold shift because acoustic stimulation, which causes temporary threshold shift, is virtually absent in natural animal habitats.

Further studies are clearly required to fully elucidate the mechanisms by which OC supporting cells control the mechanical, electrical and ionic environment of the OHCs. These 
studies are essential for understanding the normal function of OC supporting cells in cochlear sensory processing. Their role should not be ignored in the challenge to restore hearing function by repairing and regenerating sensory hair cells. Optogenetics, in its different forms, could offer new opportunities in both the investigation of normal and abnormal function in the cochlea and its eventual treatment.

\section{Acknowledgements:}

The authors thank Sarath Vijayakumar and Cassidy Nguyen for technical assistance on mouse colony management at Creighton University, and Milos Stankovic for assistance with Figure 1A.

Funding: This work was funded by the Medical Research Council (grant MR/ N004299/1).

Author contributions: IJR, ANL and JZ, conceived and designed the study. JZ designed mice with $\mathrm{ChR}$ expressing cochlear supporting cells. JAD designed $\mathrm{ChR}$ mouse cross experiments and contributed to genotyping. SL designed ex vivo measurements. ANL and IJR designed in vivo measurements. PS and SL measured and analyzed data from ex vivo experiments. VAL and IJR measured and analyzed data from in vivo experiments. SL prepared cochleae for immunohistochemistry and ZX performed cochlear immunohistochemistry. VAL organized mouse breeding at Brighton. ANL wrote computer programs. IJR and ANL wrote the paper with contributions from the other authors.

Competing interests: Authors declare no competing interests.

Data and materials availability: All data is available in the main text or the supplementary materials. Additional data related to this paper may be requested from the authors.

\section{Supplementary Materials}

Materials and Methods 


\section{References}

Lim, D. J. Functional structure of the organ of Corti: a review. Hearing Res. 22, 117 146, doi:10.1016/0378-5955(86)90089-4 (1986).

2 Robles, L. \& Ruggero, M. A. Mechanics of the Mammalian Cochlea. Physiol. Rev. 81, 1305-1352 (2001).

3 Brownell, W. E., Bader, C. R., Bertrand, D. \& de Ribaupierre, Y. Evoked mechanical responses of isolated cochlear outer hair cells. Science 227, 194-196 (1985).

4 Ashmore, J. F. A fast motile response in guinea-pig outer hair cells: the cellular basis of the cochlear amplifier. The Journal of Physiology 388, 323-347 (1987).

5 Santos-Sacchi, J. \& Dilger, J. P. Whole cell currents and mechanical responses of isolated outer hair cells. Hearing Res. 35, 143-150, doi:https://doi.org/10.1016/0378$\underline{5955(88) 90113-X}(1988)$.

6 Corey, D. P. \& Hudspeth, A. J. Ionic basis of the receptor potential in a vertebrate hair cell. Nature 281, 675-677 (1979).

7 Russell, I. J. Origin of the receptor potential in inner hair cells of the mammalian cochlea--evidence for Davis' theory. Nature 301, 334-336, doi:10.1038/301334a0 (1983).

8 Dallos, P. Cochlear amplification, outer hair cells and prestin. Curr. Opin. Neurobiol. 18, 370-376, doi:10.1016/j.conb.2008.08.016 (2008).

9 Flock, Å., Flock, B., Fridberger, A., Scarfone, E. \& Ulfendahl, M. Supporting Cells Contribute to Control of Hearing Sensitivity. The Journal of Neuroscience 19, 44984507 (1999).

10 Jacob, S., Johansson, C. \& Fridberger, A. Noise-induced alterations in cochlear mechanics, electromotility, and cochlear amplification. Pflügers Archiv - European Journal of Physiology 465, 907-917, doi:10.1007/s00424-012-1198-4 (2012).

11 Dulon, D., Blanchet, C. \& Laffon, E. Photoreleased Intracellular Ca2+ Evokes Reversible Mechanical Responses in Supporting Cells of the Guinea-Pig Organ of Corti. Biochem. Biophys. Res. Commun. 201, 1263-1269, doi:https://doi.org/10.1006/bbrc.1994.1841 (1994).

12 Bobbin, R. P. ATP-induced movement of the stalks of isolated cochlear Deiters' cells. Neuroreport 12, 2923-2926 (2001). 
40613 Lagostena, L., Cicuttin, A., Inda, J., Kachar, B. \& Mammano, F. Frequency Dependence of Electrical Coupling in Deiters" Cells of the Guinea Pig Cochlea. Cell Communication \& Adhesion 8, 393-399, doi:10.3109/15419060109080760 (2001).

14 Lukashkina, V. A., Levic, S., Lukashkin, A. N., Strenzke, N. \& Russell, I. J. A connexin30 mutation rescues hearing and reveals roles for gap junctions in cochlear amplification and micromechanics. Nature Communications 8, 14530, doi:10.1038/ncomms14530 (2017).

5 Parsa, A., Webster, P. \& Kalinec, F. Deiters cells tread a narrow path-The Deiters cells-basilar membrane junction-. Hearing Res. 290, 13-20, doi:https://doi.org/10.1016/j.heares.2012.05.006 (2012).

16 Motallebzadeh, H., Soons, J. A. M. \& Puria, S. Cochlear amplification and tuning depend on the cellular arrangement within the organ of Corti. Proceedings of the National Academy of Sciences 115, 5762-5767, doi:10.1073/pnas.1720979115 (2018).

17 Cox, B. C., Liu, Z., Lagarde, M. M. M. \& Zuo, J. Conditional Gene Expression in the Mouse Inner Ear Using Cre-loxP. JARO 13, 295-322, doi:10.1007/s10162-012-03245 (2012).

18 Walters, B. J. et al. In Vivo Interplay between p27Kip1, GATA3, ATOH1, and POU4F3 Converts Non-sensory Cells to Hair Cells in Adult Mice. Cell Reports 19, 307-320, doi:https://doi.org/10.1016/j.celrep.2017.03.044 (2017).

19 Hayashi, T., Ray, C. A., Younkins, C. \& Bermingham-McDonogh, O. Expression patterns of FGF receptors in the developing mammalian cochlea. Dev. Dyn. 239, 1019-1026, doi:10.1002/dvdy.22236 (2010).

20 Nagel, G. et al. Channelrhodopsin-1: A Light-Gated Proton Channel in Green Algae. Science 296, 2395-2398, doi:10.1126/science.1072068 (2002).

21 Nagel, G. et al. Channelrhodopsin-2, a directly light-gated cation-selective membrane channel. Proceedings of the National Academy of Sciences 100, 13940-13945, doi:10.1073/pnas.1936192100 (2003).

22 Johnstone, B. M., Patuzzi, R., Syka, J. \& Syková, E. Stimulus-related potassium changes in the organ of Corti of guinea-pig. The Journal of Physiology 408, 77-92, doi:10.1113/jphysiol.1989.sp017448 (1989).

23 Mistrík, P. \& Ashmore, J. F. Reduced Electromotility of Outer Hair Cells Associated with Connexin-Related Forms of Deafness: An In silico Study of a Cochlear Network Mechanism. JARO 11, 559-571, doi:10.1007/s10162-010-0226-3 (2010). 
24 Boettger, T. et al. Deafness and renal tubular acidosis in mice lacking the $\mathrm{K}-\mathrm{Cl}$ cotransporter Kcc4. Nature 416, 874-878, doi:10.1038/416874a (2002).

25 Boettger, T. et al. Loss of K-Cl co-transporter KCC3 causes deafness, neurodegeneration and reduced seizure threshold. The EMBO Journal 22, 5422-5434, doi:10.1093/emboj/cdg519 (2003).

26 Jagger, D. J. \& Forge, A. Compartmentalized and Signal-Selective Gap Junctional Coupling in the Hearing Cochlea. The Journal of Neuroscience 26, 1260-1268, doi:10.1523/jneurosci.4278-05.2006 (2006).

27 Cheatham, M., Naik, K. \& Dallos, P. Using the Cochlear Microphonic as a Tool to Evaluate Cochlear Function in Mouse Models of Hearing. JARO - Journal of the Association for Research in Otolaryngology 12, 113-125, doi:10.1007/s10162-0100240-5 (2011).

28 Cody, A. R. \& Russell, I. J. Acoustically induced hearing loss: Intracellular studies in the guinea pig cochlea. Hearing Res. 35, 59-70, doi:10.1016/0378-5955(88)90040-8 (1988).

29 Tritsch, N. X., Yi, E., Gale, J. E., Glowatzki, E. \& Bergles, D. E. The origin of spontaneous activity in the developing auditory system. Nature $\mathbf{4 5 0}, 50-55$, doi:10.1038/nature06233 (2007).

30 Sirko, P., Gale, J. E. \& Ashmore, J. F. Intercellular Ca2+ signalling in the adult mouse cochlea. The Journal of Physiology 597, 303-317, doi:10.1113/jp276400 (2019).

31 Yu, N. \& Zhao, H.-B. Modulation of Outer Hair Cell Electromotility by Cochlear Supporting Cells and Gap Junctions. PLoS ONE 4, e7923, doi:10.1371/journal.pone.0007923 (2009).

32 Kakehata, S. \& Santos-Sacchi, J. Membrane tension directly shifts voltage dependence of outer hair cell motility and associated gating charge. Biophys. J. 68, 2190-2197, doi:https://doi.org/10.1016/S0006-3495(95)80401-7 (1995).

33 Ramamoorthy, S. \& Nuttall, Alfred L. Outer Hair Cell Somatic Electromotility In Vivo and Power Transfer to the Organ of Corti. Biophys. J. 102, 388-398, doi:10.1016/j.bpj.2011.12.040 (2012).

34 Fridberger, A. et al. Organ of Corti Potentials and the Motion of the Basilar Membrane. The Journal of Neuroscience 24, 10057-10063, doi:10.1523/jneurosci.2711-04.2004 (2004). 
47235 Lagostena, L. \& Mammano, F. Intracellular calcium dynamics and membrane conductance changes evoked by Deiters' cell purinoceptor activation in the organ of Corti. Cell Calcium 29, 191-198, doi:https://doi.org/10.1054/ceca.2000.0183 (2001).

\section{Supplementary Materials only:}

1 Cox, B. C., Liu, Z., Lagarde, M. M. M. \& Zuo, J. Conditional Gene Expression in the Mouse Inner Ear Using Cre-loxP. JARO 13, 295-322, doi:10.1007/s10162-012-03245 (2012).

2 Walters, B. J. et al. In Vivo Interplay between p27Kip1, GATA3, ATOH1, and POU4F3 Converts Non-sensory Cells to Hair Cells in Adult Mice. Cell Reports 19, 307-320, doi:https://doi.org/10.1016/j.celrep.2017.03.044 (2017).

3 Legan, P. K. et al. A Targeted Deletion in [alpha]-Tectorin Reveals that the Tectorial Membrane Is Required for the Gain and Timing of Cochlear Feedback. Neuron 28, 273-285, doi:10.1016/s0896-6273(00)00102-1 (2000).

4 Wu, T. et al. Optogenetic Control of Mouse Outer Hair Cells. Biophys. J. 110, 493502, doi:http://dx.doi.org/10.1016/j.bpj.2015.11.3521 (2016).

5 Zhang, F., Wang, L.-P., Boyden, E. S. \& Deisseroth, K. Channelrhodopsin-2 and optical control of excitable cells. Nat. Methods 3, 785-792, doi:10.1038/nmeth936 (2006). 
4996 Aravanis, A. M. et al. An optical neural interface:in vivocontrol of rodent motor 500 cortex with integrated fiberoptic and optogenetic technology. Journal of Neural Engineering 4, S143-S156, doi:10.1088/1741-2560/4/3/s02 (2007).

502

7 Lukashkin, A. N., Bashtanov, M. E. \& Russell, I. J. A self-mixing laser-diode interferometer for measuring basilar membrane vibrations without opening the cochlea. J. Neurosci. Methods 148, 122-129, doi:10.1016/j.jneumeth.2005.04.014 (2005). 


\section{Figures}

a

Reticular lamina (RL)

Outer pillar cell (OPC)

Spaces of Nuel (SN)

Basilar membrane (BM)

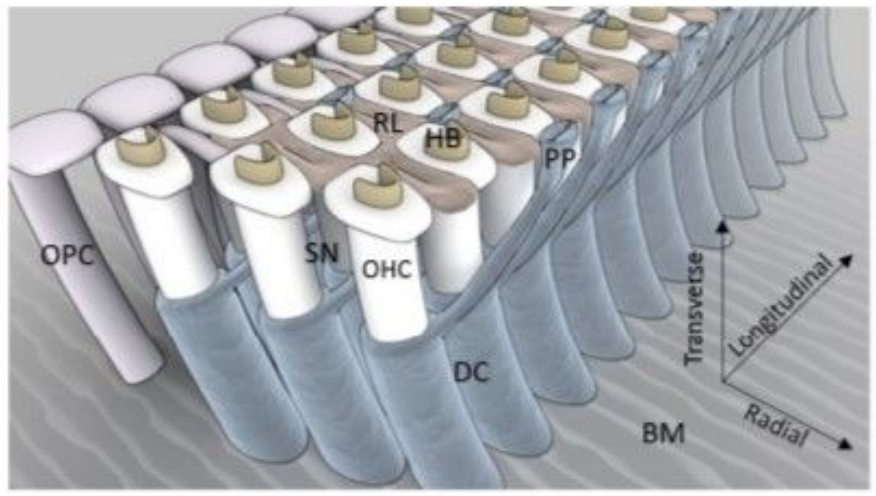

Hair bundle (HB)

Outer hair cell (OHC)

Phalangeal process (PP)

Deiters' cell (DC)

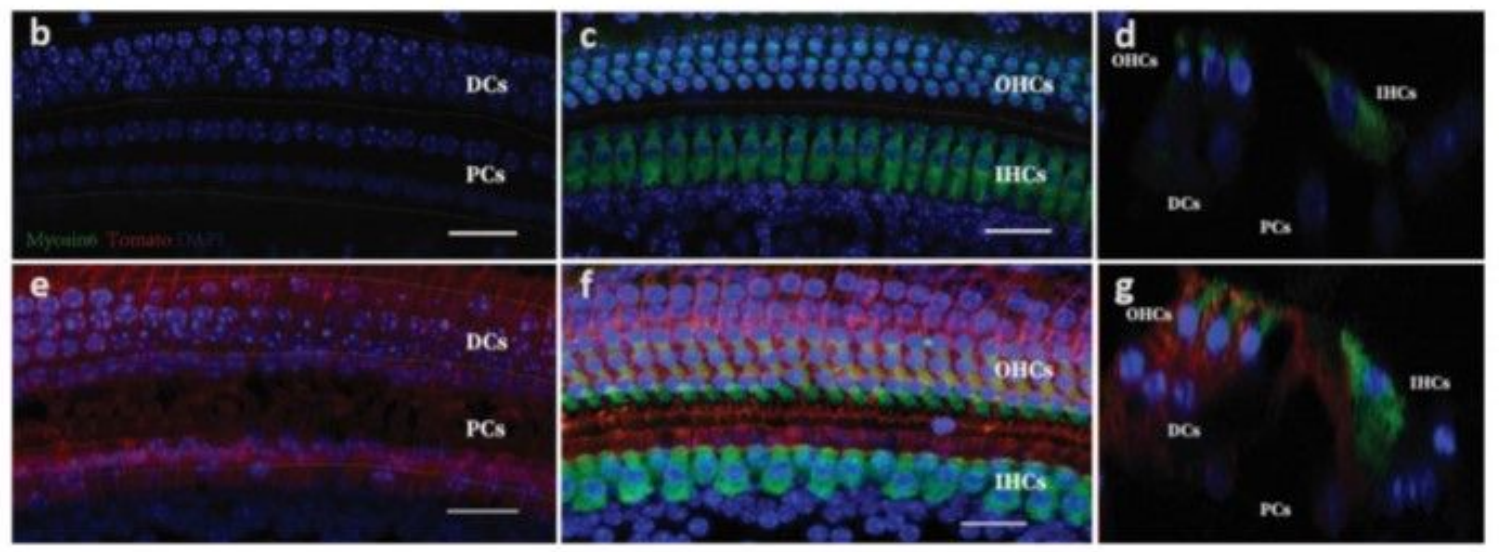

\section{Figure 1}

Schematic of the organ of Corti and expression of COP-tdTomato ChR in its supporting cells. (a) Schematic of the radially distal region of the organ of Corti. $(b-g)$ ChR expression in the DCs and inner and outer pillar cells (PCs). Fgfr3-iCreERT2 ; COP-tdTomato mice were induced with tamoxifen (TMX) at P12/13 and analyzed at postnatal-day 28. (b-d) Fgfr3-iCreERT2- ; COP-tdTomato+ control mice. (e-g) Fgfr3-iCreERT2+ ; COPtdTomato+ experimental mice. $(b, c, e, f)$ wholemount cochlear basal turns. $(b, e)$ supporting cell layers. $(c, f)$ projections of supporting cell and hair cell layers. $(d, g)$ optical cross-sections in $(b, c)$ and $(e, f)$ respectively. IHCs: inner hair cells. Green: Myo6; blue: DAPI; red: autofluorescence of tdTomato. Scale bar $=20 u m$. 

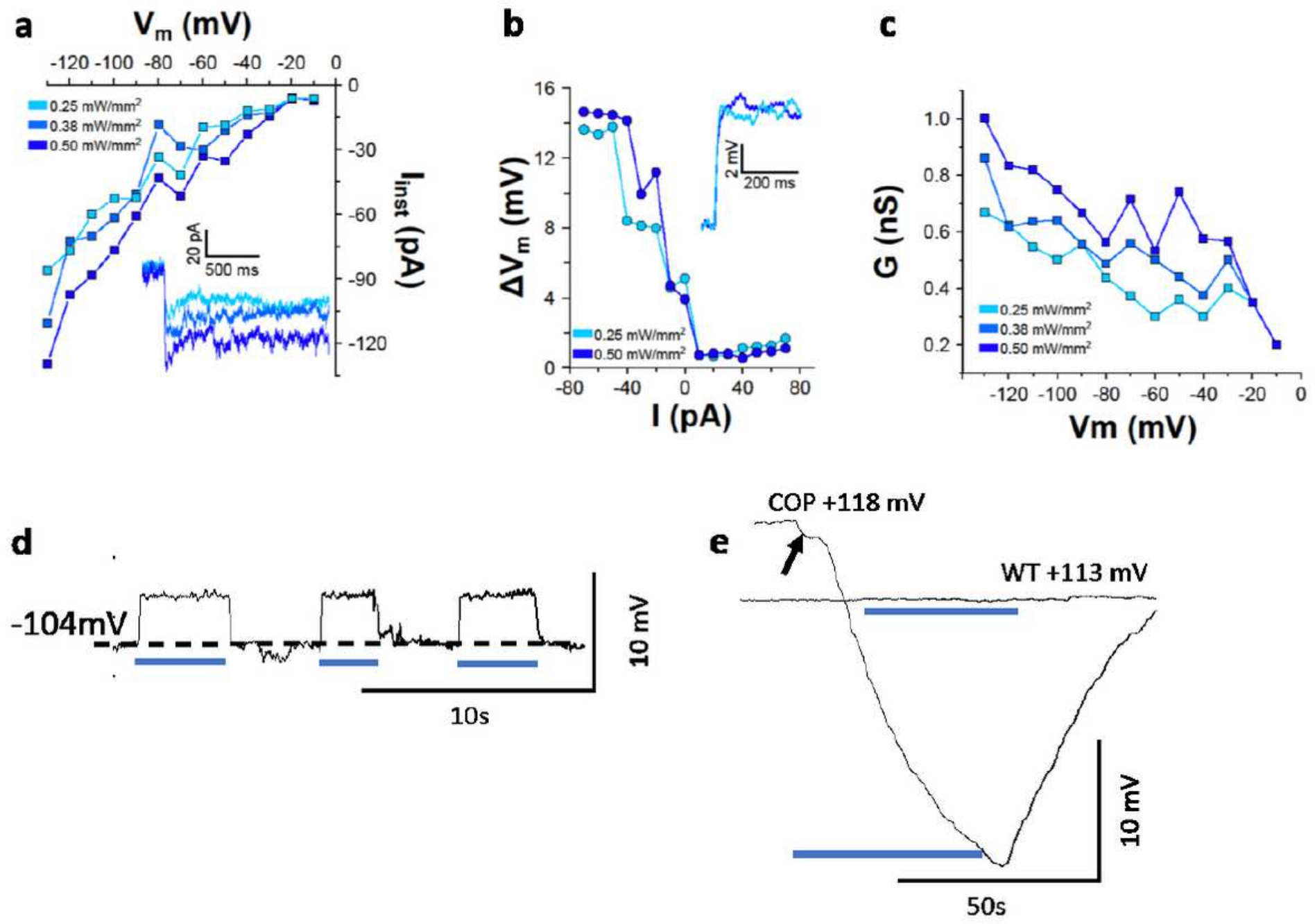

Figure 2

Cochlear illumination depolarizes COP mouse DC membrane potentials and reduces the endocochlear potential. (a) Ex vivo whole-cell patch recordings of current-voltage (I-V) plot: peak current amplitudes of a DC elicited in response to laser illumination at different power densities, as functions of membrane potential. Inset: Inward current traces at different laser power densities (-90 mV holding potential). (b) Ex vivo light-induced potential-current $(\Delta \mathrm{V}-\mathrm{I})$ relationship of a $\mathrm{DC}$ : membrane potential changes $(\Delta \mathrm{V})$ during laser illumination as functions of injected currents. Light-induced depolarizations were elicited during negative current injection. Inset: whole-cell current-clamp recording (resting membrane potential $=-50$ $\mathrm{mV}$ ) of light elicited depolarization with different laser power densities. (c) Conductance $\mathrm{G}(\mathrm{nS})$ as a function of membrane potential $\mathrm{V}(\mathrm{mV})$ at 3 different laser power densities using data in (a) at $-130 \mathrm{mV}$ holding potential. Increasing laser power increased the DC membrane conductance $(0.67,0.86$ and $1 \mathrm{nS}$ respectively). (d) In vivo intracellular recordings from presumed DCs showing membrane depolarizations (4.2 $\pm 0.3 \mathrm{mV}, \mathrm{n}=8$ cochleae) to successive periods of BM laser illumination. (e) EP recorded from scala media during BM laser illumination. COP trace arrow: onset step. WT littermate: nonresponsive to laser illumination. Blue bars in $\mathrm{d}$ and e: periods of $100 \mu \mathrm{m}$ diameter, $0.25 \mathrm{mWmm}-2,470 \mathrm{~nm}$ laser illumination. 


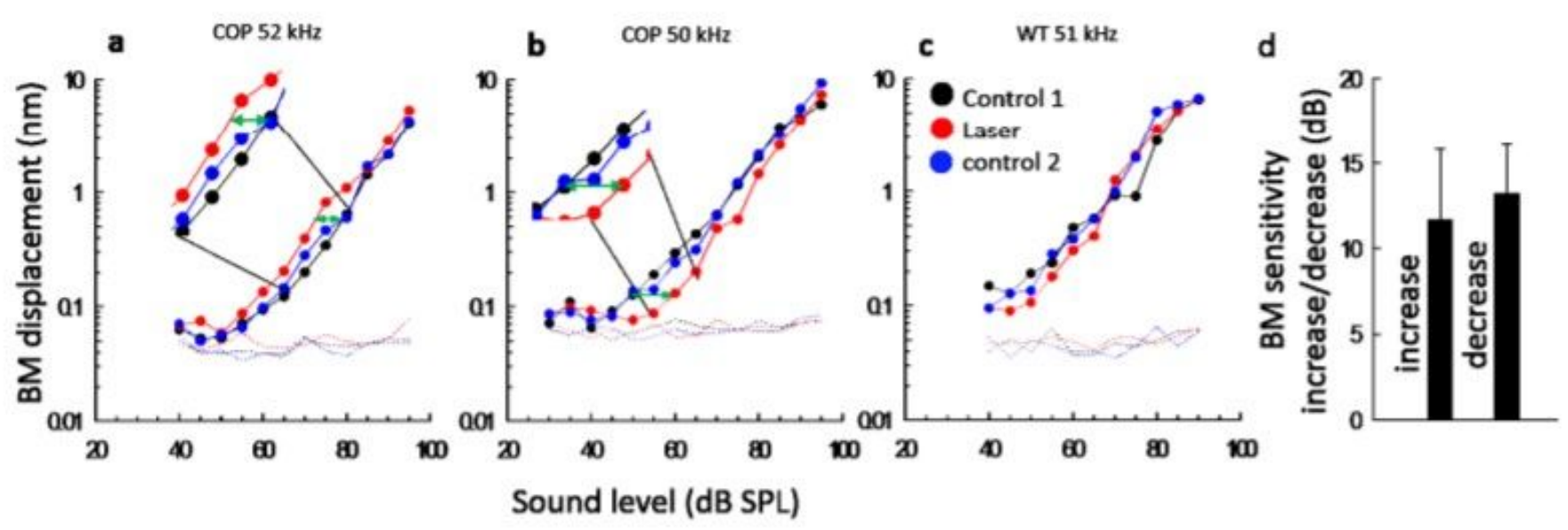

\section{Figure 3}

BM Laser illumination alters the sensitivity of cochlear mechanical responses of COP mice over their entire dynamic range. (a-c) BM displacement as functions of SPL from two COP $(a, b)$ and one WT (c) mice at the $\mathrm{CF}$ tone frequencies indicated. Measurements were, made before (black, control 1), during (red, laser), and following (blue, control 2) BM laser illumination (see c). Dotted lines: measurement noise floors Green arrows $(a, b)$ : maximum sensitivity change (expanded views: insets). d. Mean \pm S.D of maximum 139 increases in sensitivity $(11.7 \pm 4.1 \mathrm{~dB}, \mathrm{n}=7$ cochleae) and decreases (13.2 $\pm 2.9 \mathrm{~dB}, \mathrm{n}=9)$ of BM displacement (green arrows $a, b$ ) during BM laser illumination in COP mice. There was no visible increase or decrease of BM sensitivity in WT littermates $(-1.3 \pm 2.2 \mathrm{~dB}, \mathrm{n}=6$ cochleae). Laser illumination: $100 \mathrm{~mm}$ beam diameter, wavelength: $473 \mathrm{~nm}$, power density $=0.25 \mathrm{mWmm}-2$ apart from $\mathrm{C}=0.75$ $\mathrm{mWmm}-2142$. All measurements from different cochleae, uncompensated for middle-ear and electrode characteristics.

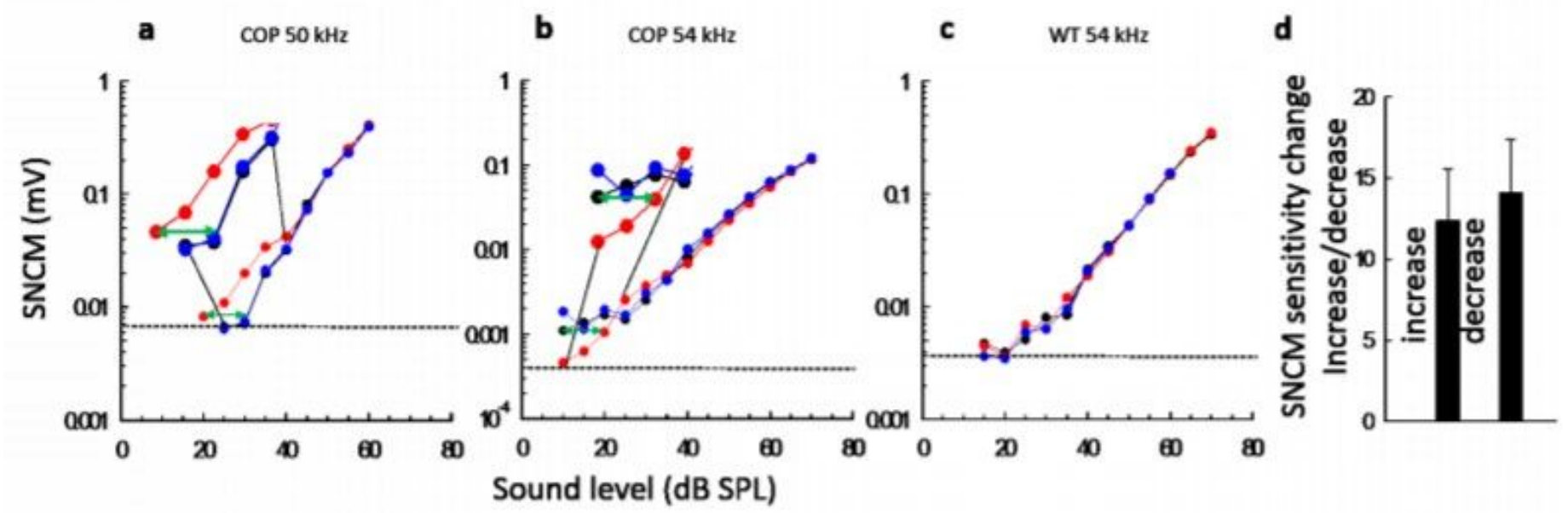

Figure 4 
BM Laser illumination alters the sensitivity of cochlear electrical responses that are subject to cochlear amplification in COP mice. (a-b) Organ of Corti cochlear microphonic potential recorded from the SN (SNCM); magnitude as functions of SPL for sound stimulation at the CF frequencies indicated. Measurements made before (black), during (red), and following (blue) BM laser illumination (see 3c). Dotted lines: mean measurement noise floors. Green arrows: maximum sensitivity change (expanded views: insets). $\mathrm{d}$. Mean \pm S.D of maximum increases in sensitivity (12.4 $\pm 3.2 \mathrm{~dB}, \mathrm{n}=8$ cochleae) and decreases $(14.1 \pm 3.3 \mathrm{~dB}, \mathrm{n}=7$ ) of SNCM (green arrows $a, b)$ during BM laser illumination in COP mice. There was no visible increase or decrease of BM sensitivity in WT littermates $(0.7 \pm 1.8 \mathrm{~dB}, \mathrm{n}=5$ cochleae). Laser illumination; $100 \mathrm{~mm}$ beam diameter, wavelength: $473 \mathrm{~nm}$, a,b; power density $=0.25$ mWmm-2 , C; $=0.75$ mWmm-2 169. All measurements from different cochleae, uncompensated for middle-ear and electrode characteristics.
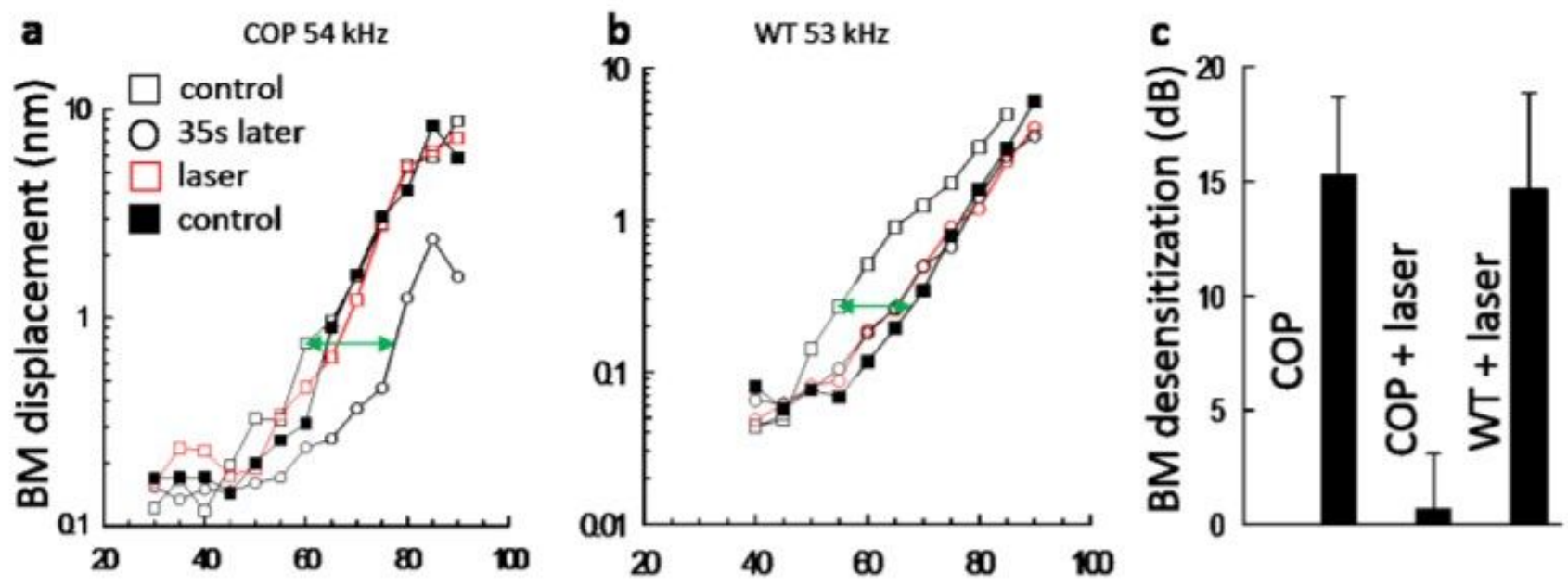

Sound level (dB SPL)

\section{Figure 5}

BM Laser illumination of COP mice accelerates recovery of temporarily desensitized cochleae. a: BM displacement level functions measured in COP mouse in quick succession (35s intervals) after control (open squares), without required 5-minute interval, becomes desensitized (open circles). Sensitivity returns during the level run with BM laser illumination (red squares), measured $35 \mathrm{~s}$ after the open circle level run. Sensitivity is sustained during control level run (black solid squares), measured $35 \mathrm{~s}$ after laser run. b. BM displacement level functions measured in WT mouse using the same regime as for the COP mouse in a. Maximum sensitivity change: green arrows $(a, b)$. c. Bar graphs: maximum change in BM displacement sensitivity to $\mathrm{CF}$ tone level functions presented successively in $35 \mathrm{~ms}$ intervals in COP mice without BM laser illumination ( $15.3 \pm 3.4 \mathrm{~dB}, \mathrm{n}=6$ cochleae) and in COP $(0.7 \pm 2.4 \mathrm{~dB}, \mathrm{n}=6)$ and WT mice $(14.7 \pm 4.1 \mathrm{~dB}, \mathrm{n}=5)$ with laser illumination. Laser illumination: $100 \mathrm{~mm}$ beam diameter, wavelength: $473 \mathrm{~nm}$, power density $=0.25 \mathrm{mWmm}-2$ apart from $\mathrm{c}=0.75 \mathrm{mWmm}-2217$. All measurements uncompensated for middle-ear and electrode characteristics. 

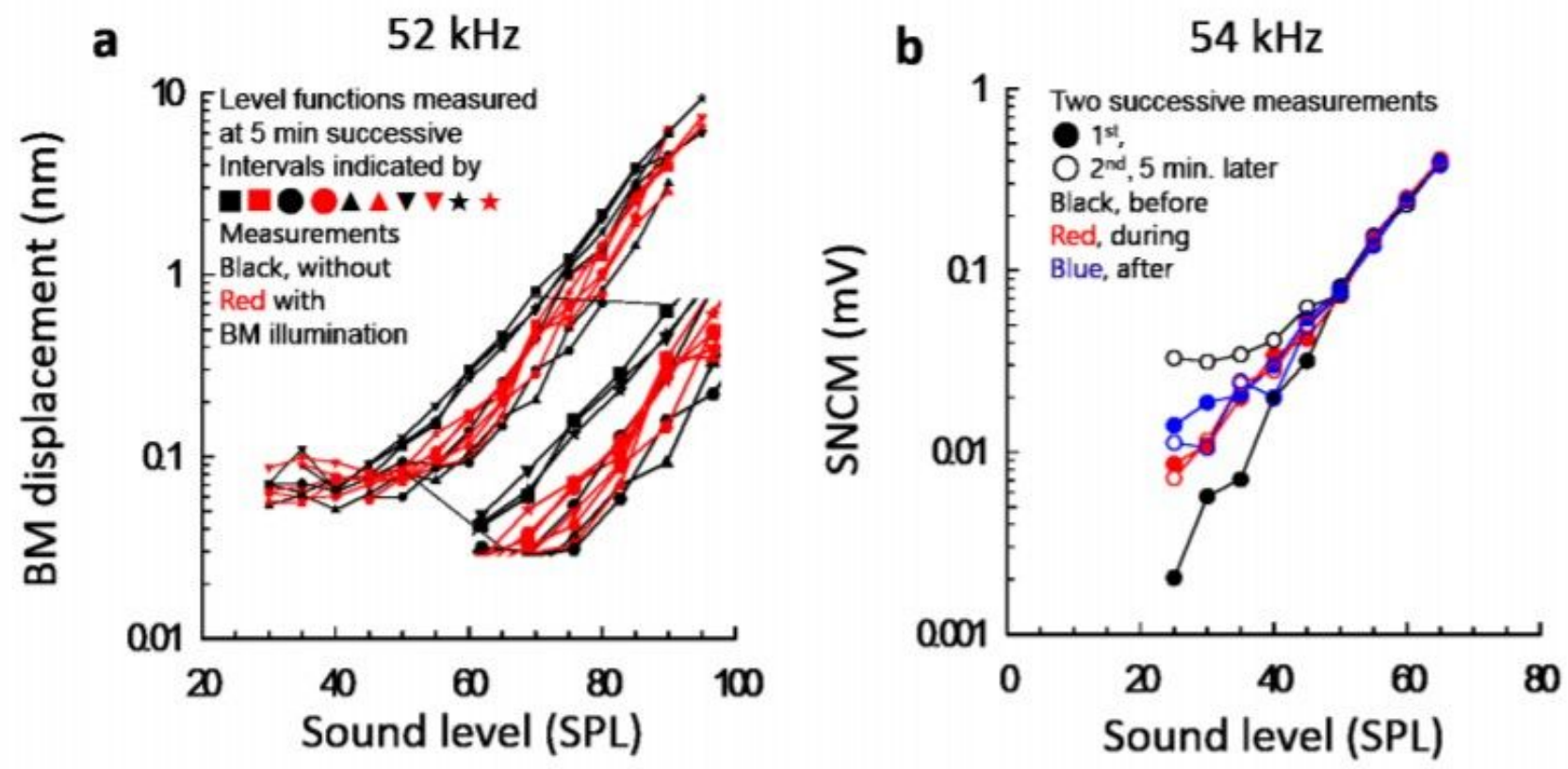

Figure 6

OC supporting cells mediate homeostatic control of mechanical and electrical cochlear sensitivity. (a) BM displacement level functions for CF tones, with expanded view (arrows), showing 10 successive presentations (indicated by different symbols), measured at 5-minute intervals without and with BM laser illumination of a representative cochlea. (b) SNCM level functions for CF tones showing two successive presentations at 5-minute intervals measured during and following BM laser illumination, $473 \mathrm{~nm}, 0.25$ $\mathrm{mWmm}-2$

a

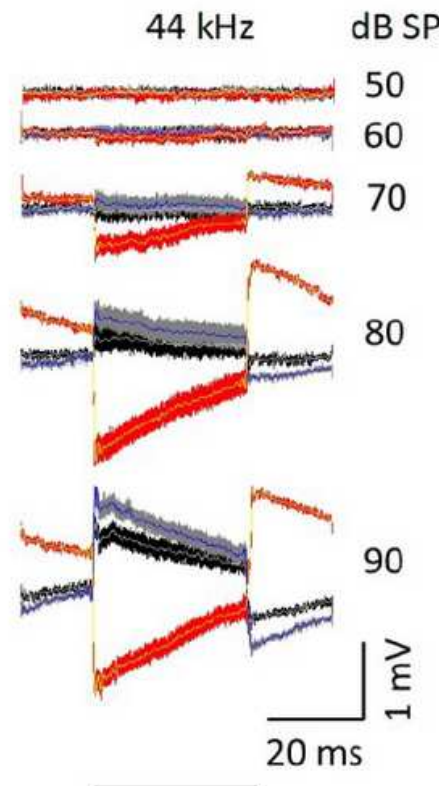

b $\quad 54 \mathrm{kHz} \quad \mathrm{dB}$ SPL

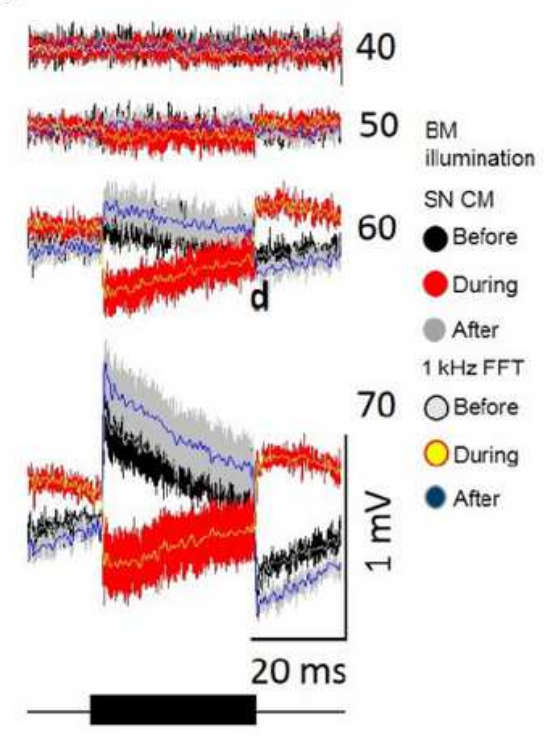

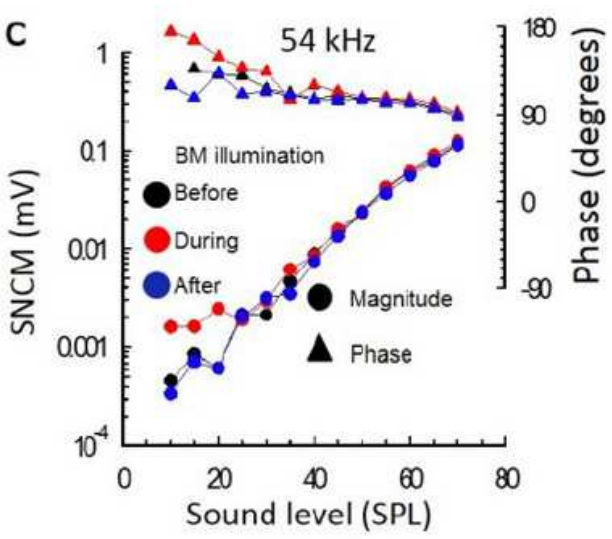




\section{Figure 7}

Light excitation of OC supporting cells changes the polarity of the tonic component of the OCCM in COP mice. $(a, b)$ Voltage responses (average of 20 presentations) to just below CF $(44 \mathrm{kHz})$ and CF $(54 \mathrm{kHz})$ tones recorded from the SN in different cochleae for the SPLs indicated before, during and after BM illumination. Superimposed traces: $1 \mathrm{kHz}$ low-pass FFT filtered responses (tonic component of OCCM). (c) SNCM magnitude and phase level functions for data in (b). BM laser illumination: $473 \mathrm{~nm}, 0.25$ mWmm-2 251 . Bars beneath traces indicate stimulating tone burst.

\section{Supplementary Files}

This is a list of supplementary files associated with this preprint. Click to download.

- SuppIMethods131020.pdf 